\title{
Agriculture of American Aborigines
}

\author{
By Jonas M. Poweshitek
}

If we could return to the days of Columbus, more than 400 years ago, we would find, as he did, that corn was already under intensive cultivation in America.

Wide fields of this vital crop stretched through the present United States into Mexico and the Carribeans, the result of countless generations of careful nurturing. Year after year, the Indian had tended his cornfields until he had developed, through great care and good fortune, all five basic types of corn.

This vital food, second only to wheat in importance, is a true gift of the Indian. The debt to the Indian is greater than it seems, for corn has never been found in any wild form whatsoever; only the Indian's care has preserved this basic food. The Indian had all five basic types of corn-dent, flint, flour, sweet and popcorn, which is proof of his careful cultivation and interest.

Agriculture is standard, for food is basic for life and culture. The white man has not developed in America a single major agricultural product from its wild growth. In contrast, the American Indian has developed more than 20 important crops, besides cultivating and utilizing many wild growths. In the overall aggregate, the American Indian's contribution to the world food supply accounts for more than half of our present agricultural wealth.

Primitive Farming Methods

The Indian method farming was very primitive. They did not plow up the earth; they retained the rich top soil by making hills for corn-other soil was not disturbed, thus keeping it from washing or eroding. They kept the weeds off by pulling up weeds that grew around the stalks. Bugs did not bother their crops, because other weeds that bugs live on were left alone. 
The same hills were used year after year; to loosen the dirt they had a hoe made from flint stone with wooden handle 4 or 5 feet long. Sharp sticks were also used in the loosening and cultivation of corn and other crops.

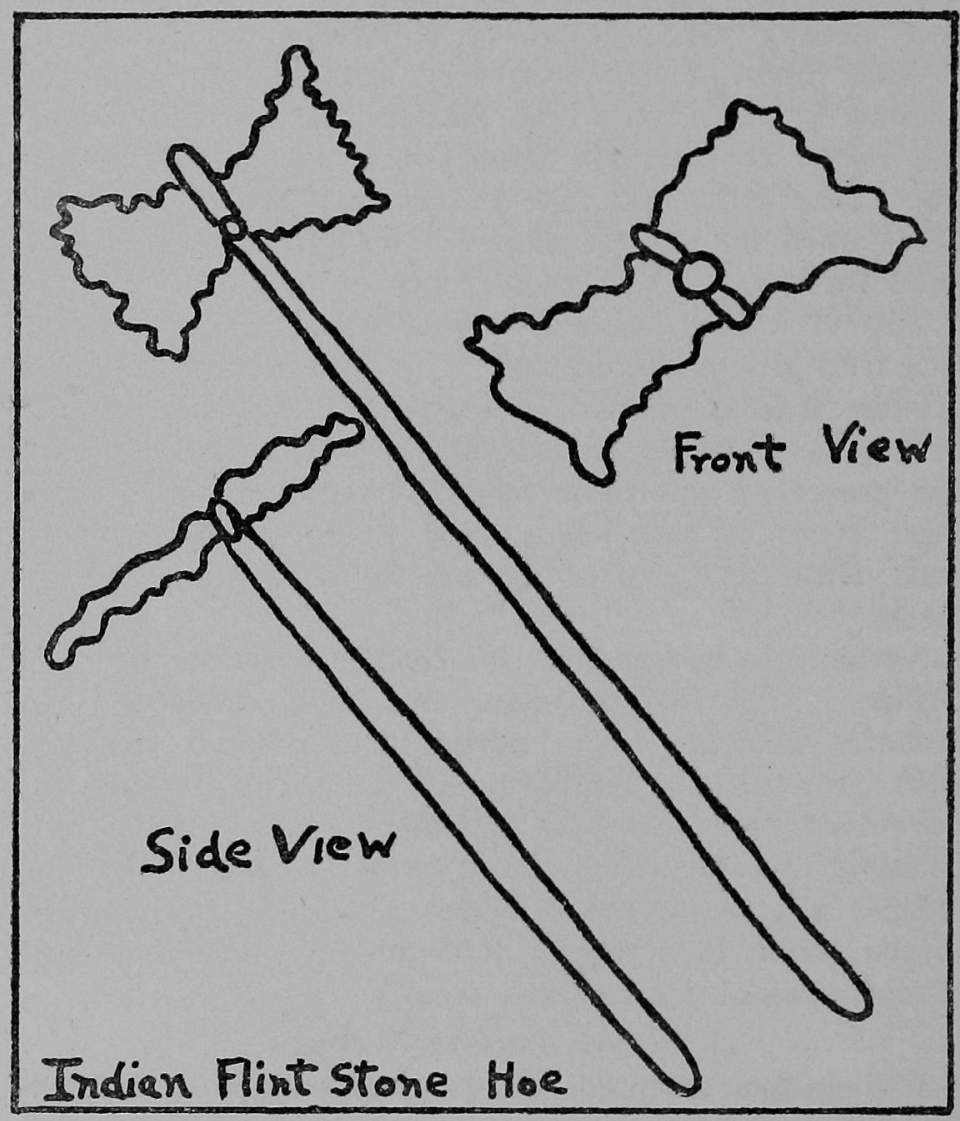


Copyright of Annals of Iowa is the property of State of Iowa, by \& through the State Historical Society of Iowa and its content may not be copied or emailed to multiple sites or posted to a listserv without the copyright holder's express written permission. However, users may print, download, or email articles for individual use. 